\title{
Lopinavir-Ritonavir in SARS-CoV-2 Infection and Drug-Drug Interactions with Cardioactive Medications
}

\author{
Shubham Agarwal $^{1}$ (D) Sanjeev Kumar Agarwal $^{2}$ (D) \\ Accepted: 1 September 2020 / Published online: 12 September 2020 \\ (C) Springer Science+Business Media, LLC, part of Springer Nature 2020
}

\begin{abstract}
Lopinavir-ritonavir combination is being used for the treatment of SARS-CoV-2 infection. A low dose of ritonavir is added to other protease inhibitors to take advantage of potent inhibition of cytochrome (CYP) P450 3A4, thereby significantly increasing the plasma concentration of coadministered lopinavir. Ritonavir also inhibits CYP2D6 and induces CYP2B6, CYP2C19, CYP2C9, and CYP1A2. This potent, time-dependent interference of major hepatic drug-metabolizing enzymes by ritonavir leads to several clinically important drug-drug interactions. A number of patients presenting with acute coronary syndrome and acute heart failure may have SARS-CoV-2 infection simultaneously. Lopinavir-ritonavir is added to their prescription of multiple cardiac medications leading to potential drug-drug interactions. Many cardiology, pulmonology, and intensivist physicians have never been exposed to clinical scenarios requiring co-prescription of cardiac and antiviral therapies. Therefore, it is essential to enumerate these drug-drug interactions, to avoid any serious drug toxicity, to consider alternate and safer drugs, and to ensure better patient care.
\end{abstract}

Keywords COVID-19 · SARS-CoV-2 · Drug interactions $\cdot$ Lopinavir-ritonavir · Cardiovascular therapy

\section{Introduction}

On December 31, 2019, the World Health Organization office in China was informed of a few cases of pneumonia of unknown cause originating from the city of Wuhan, Hubei province in China [1]. Over the next 3 months, severe acute respiratory syndrome coronavirus-2 (SARS-CoV-2) infection, commonly called COVID-19 rapidly evolved into a pandemic. Preexisting cardiovascular (CV) disease (14.5\%) and CV risk factors like hypertension $(31.2 \%)$ and diabetes $(10.1 \%)$ are commonly present in these patients $[2,3]$. In addition, there are several potential mechanisms for acute effects of SARS-CoV2 infection on the CV system causing acute cardiac injury [4]. Some patients presenting with acute coronary syndrome (ACS)

Sanjeev Kumar Agarwal

skacardio@yahoo.com

Shubham Agarwal

shubhamagarwaldr@gmail.com

1 Department of Internal Medicine, Rosalind Franklin University of Medicine and Science Chicago Medical School, North Chicago, IL, USA

2 Department of Cardiology, Rashid hospital, Dubai, United Arab Emirates and/or acute heart failure (AHF) for the first time turn out to be positive for COVID-19. They may rapidly develop symptoms of SARS-CoV-2 pneumonia and require the addition of antiviral therapies. Unmonitored use of antiviral therapies is known to cause cardiac complications [5]. Protease inhibitor (PI) ritonavir (RTV) is competitive and non-competitive, irreversible inhibitor of CYP3A4 leading to important drug-drug interactions (DDI). The data from other cytochrome inhibitors like ketoconazole may not be extrapolated to RTV as ketoconazole is only a competitive reversible inhibitor of CYP3A4. The DDIs of PIs are common but avoidable and impose a significant increase in healthcare costs. In a study of people living with HIV, $16.8 \%$ had at least one DDI in a year time with a significantly higher risk in those receiving PIs [6]. This study aims to extract all the available data on DDI between lopinavir/ritonavir (L/R) and various cardiac drugs from studies in the HIV population and other groups of patients, for the judicious and safe use of combination therapy.

\section{Methods}

The electronic database of PubMed was searched using medical subject headings (MeSH) terms and all articles reporting interactions between lopinavir-ritonavir and individual 
cardiac medications were considered. Articles that were published after 1980 until present were considered.

An additional literature search was done through the reference list and citations of selected articles. Published articles and guidelines were given priority over product monograph of drugs to extract relevant information. The flow diagram for 101 articles included in this study is shown in Fig. 1.

\section{Discussion}

\section{Lopinavir/Ritonavir}

A number of clinical trials are underway to assess the efficacy and safety of antiviral therapies in SARS-CoV-2 infection. It has been shown that PIs bind to the active site of SARS-CoV $\mathrm{M}^{\text {pro }}$ (main protease), a key enzyme for coronavirus replication [7, 8]. Lopinavir/ritonavir (L/R), an HIV-based PI, is also undergoing many clinical trials (ClinicalTrials.gov identifier: https://clinicaltrials.gov/ct2/show/NCT04261270, https:// clinicaltrials.gov/ct2/show/NCT04295551, https:// clinicaltrials.gov/ct2/show/NCT04275388, NCT04372628 and NCT04328012). There are conflicting reports about the efficacy of these drugs. A recently published randomized, controlled, open-label trial comparing $\mathrm{L} / \mathrm{R}$ with standard care therapy in patients with severe COVID-19 failed to show a difference in, time to clinical improvement (HR 1.31) or mortality ( $19.2 \%$ vs. $25.0 \%$; difference, -5.8 percentage points; $95 \% \mathrm{CI},-17.3$ to 5.7 ) at 28 days [9]. However, in a modified intention to treat analysis, the median time to clinical improvement was reduced in the active drug group and mortality was also reduced in patients treated early after symptom onset. Similarly, in a previously published study [10] in patients with SARS-CoV, early treatment with $\mathrm{L} / \mathrm{R}$ was associated with a reduction in mortality $(2.3 \%)$ and intubation rates $(0 \%)$ compared with matched controls (15.6\% and $11.0 \%$ respectively, $p<0.05)$ and these benefits of $\mathrm{L} / \mathrm{R}$ were lost in patients who received it as rescue therapy. Thus, the high-quality evidence is currently lacking; however, its use in COVID-19 continues in many countries approved by the local relevant authorities.

Most of the current day knowledge about $\mathrm{L} / \mathrm{R}$ is derived from its use in patients of acquired immune deficiency syndrome (AIDS). These patients are at higher risk of coronary heart disease than the general population [11] and over years, experience has accumulated about co-management of cardiovascular diseases in HIV patients.

\section{Lopinavir/Ritonavir + Antiplatelet Agents}

Dual antiplatelet therapy comprising of a P2Y12-receptor inhibitor with aspirin is the critical component of the management of patients with ACS. In addition, a large number of patients with diabetes mellitus, atherosclerotic cardiovascular, and peripheral vascular disease are on antiplatelet drugs [12]. Protease inhibitor use was associated with increased platelet reactivity and higher rate of high on-treatment platelet reactivity (HTPR). Following DDIs have been observed between L/ $\mathrm{R}$ and antiplatelet agents.

Aspirin Aspirin is rapidly deacetylated to salicylic acid and then metabolized by glucuronidation. The inducing effect of RTV on glucuronidation may have an impact on the clearance
Fig. 1 Flowchart of the literature search and selection of studies

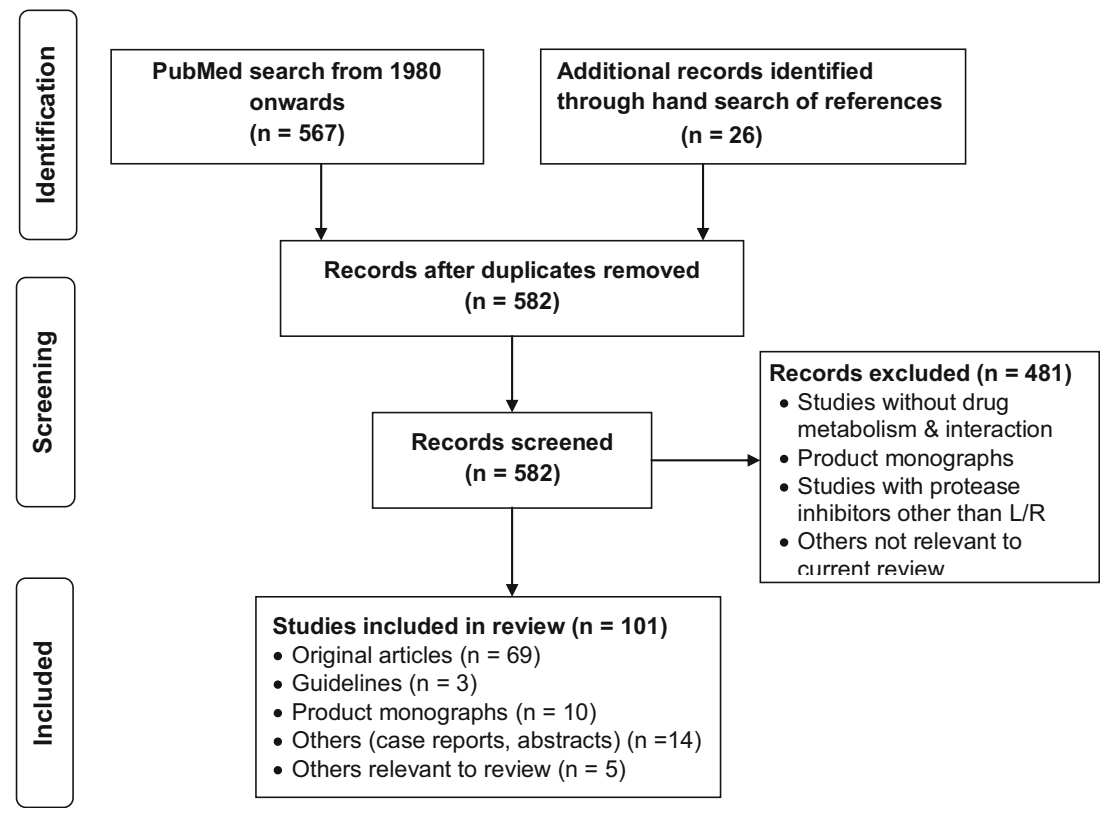


of salicylate [13], but clinically significant consequences have not been reported. Aspirin has been shown to worsen ritonavir-induced intestinal injury in experimental animals [14]. In another study, RTV was shown to cause $\geq 50 \%$ inhibition of platelet aggregation in response to arachidonic acid; however, it was not associated with an increase in bleeding time [15].

Dipyridamole Dipyridamole is metabolized by uridine glucuronosyltransferases (UGT), specifically of 1A subfamily. Coadministration with $\mathrm{L} / \mathrm{R}$ may potentially decrease dipyridamole exposure due to the induction of glucuronidation, thereby reducing the antiplatelet effect but clinically significant interaction is unlikely.

Clopidogrel Clopidogrel is a prodrug. It is converted to an active metabolite (AM) in a two-step hepatic bioactivation by multiple CYP450 isoenzymes. L/R may cause an increase in clopidogrel concentration through CYP3A4 inhibition but a reduction in the active metabolite formation. A study on the effect of RTV on clopidogrel AM in 12 healthy volunteers showed that RTV decreased the area under the concentration-time curve $\mathrm{AUC}_{0-4 \mathrm{~h}}$ of clopidogrel $\mathrm{AM}$ by $51 \%(p=0.0001)$, and the average platelet inhibition decreased from $51 \%$ without RTV to $31 \%$ with RTV (mean difference $90 \% \mathrm{CI}-27 \%$ to $-12 \%, p=0.0007$ ) [16]. The maximal platelet inhibition by clopidogrel was also reduced from 60 to $40 \%$ with concurrent RTV (mean difference $90 \%$ CI $-29 \%$ to $-11 \%$ ). Thus, inhibition of platelet aggregation by clopidogrel was significantly reduced by RTV. A diminished clopidogrel response after exposure to RTV may increase the risk of stent thrombosis [17].

Close clinical and laboratory monitoring for evidence of diminished antiplatelet effects is recommended.

Prasugrel Prasugrel is a prodrug that requires conversion to an AM by CYP3A4 and 2B6 before binding to platelet P2Y12 receptor to irreversibly inhibit platelets. A pharmacokinetic (PK) study monitoring the effect of RTV on prasugrel AM in healthy volunteers showed that RTV significantly decreased prasugrel $\mathrm{AM} \mathrm{AUC}_{0-6 \mathrm{~h}}$ and maximum concentration $\left(C_{\max }\right)$ by $45 \%$ and $38 \%$, respectively, while time to $C_{\max }(t-$ $\max )$ and half time $\left(t_{1 / 2}\right)$ were not affected [18]. However, only a single dose of prasugrel was given and the effect of the interaction on platelet inhibition was not assessed. An in vitro study by Daali et al. also found significant inhibition of prasugrel bioactivation by RTV [19]. The impact of RTV on the comparative efficacy of prasugrel vs. clopidogrel AMs and their PKs was studied by Marsousi et al. [20]. The AUC and $C_{\max }$ of prasugrel AM were reduced by $52 \%$ and $43 \%$ respectively in HIV patients on RTV compared with healthy volunteers on prasugrel only. However, it did not translate into insufficient platelet inhibition by prasugrel. Conversely, RTV decreased the exposure to clopidogrel AM significantly (3.2fold lower AUC and $C_{\max }$ ) and resulted in inadequate platelet inhibition in $44 \%$ of HIV patients. This differential impact of RTV on platelet inhibition by clopidogrel and prasugrel is possibly a reflection of the higher antiplatelet effect of prasugrel compared with clopidogrel in patients of stable coronary artery disease [21], ACS [22], including those undergoing percutaneous coronary intervention [23]. In a case report by Bravo et al., clopidogrel was replaced by prasugrel, after a patient on aspirin and clopidogrel with RTV developed stent thrombosis [17]. Subsequently, there was no further major adverse cardiac event.

Thus, prasugrel may be preferred to clopidogrel in the presence of RTV-boosted regimens, unless patients have a clinical condition (history of transient ischemic attack or stroke, age $>$ 75 years, and body weight $<60 \mathrm{~kg}$ ), which contraindicates its use. In such a clinical scenario, an alternative antiplatelet agent should be considered with dose adjustment by platelet function monitoring.

Ticagrelor Ticagrelor is a direct-acting, reversible P2Y12receptor antagonist. It is not a prodrug and does not require metabolic activation for antiplatelet activity. Still, it is extensively metabolized by CYP3A4 and 3A5 and its active and approximately equipotent metabolite is about a third that of ticagrelor. Inhibition of CYP3A-mediated metabolism of ticagrelor by $\mathrm{L} / \mathrm{R}$ may increase the antiplatelet effects of ticagrelor [24]. In a study of human volunteers, platelet inhibition was nearly complete despite the administration of a fourfold lower dose of ticagrelor [25]. The absolute platelet reactivity unit (PRU) was 11.8 (4.7-18.9), $4 \mathrm{~h}$ after a single dose of $180 \mathrm{mg}$ ticagrelor compared with 18.1 (5.3-30.8) after $45 \mathrm{mg}$ ticagrelor coadministered with $100 \mathrm{mg} \operatorname{RTV}(p=0.15)$. In patients on CYP3A4 inhibitors (RTV or cobicistat), the half-life of ticagrelor is significantly increased and it may take up to 10 days for P2Y12 test results to be restored to normal [26]. Thus, it is suggested to avoid concomitant use of ticagrelor with $\mathrm{L} / \mathrm{R}$, consider alternative antiplatelet agent, or possibly use a fourfold lower dose.

Cangrelor It is the only intravenous P2Y12 inhibitor available and is deactivated by dephosphorylation in the circulation. Cangrelor and its major metabolites do not inhibit CYP isoenzymes, and there is no interference with the hepatic metabolism of any drug.

Vorapaxar Prescription of L/R in patients on vorapaxar is expected to increase vorapaxar levels and coadministration is not recommended [27].

Glycoprotein IIb/Illa Inhibitor Tirofiban and eptifibatide are the commonly used GPIIb/IIIa inhibitors. Metabolism of tirofiban is very limited. A majority of the drug is recovered 
unchanged in the urine and feces. A majority of eptifibatide is excreted in the urine as eptifibatide and deaminated eptifibatide. Chances of DDI with L/R are unlikely.

\section{Lopinavir/Ritonavir + Lipid-Lowering Therapies}

Statins Most statins are metabolized by the CYP450 enzyme system in the liver. Lipophilic statins (e.g., lovastatin, simvastatin, atorvastatin) are substrates for CYP450, particularly CYP3A4. Hydrophilic statins (e.g., pravastatin and rosuvastatin) are not significantly metabolized by CYP450 [28]. Lopinavir/ritonavir are strong inhibitors of permeability-glycoprotein (P-gp) transporter also. In addition, two transporters, organic anion-transporting polypeptide 1B1 (OATP1B1) and breast cancer resistance protein (BCRP), also known as ATP-binding cassette (ABC) transporter G2, are also inhibited by PIs affecting transporter-mediated interaction of statins $[29,30]$. All statins gain entry into hepatocytes for their pharmacologic activity and metabolism via OATP1B1 and are eliminated through bile via the ABC transporter family. It is also known that different PIs have a differential effect on the metabolism of the same statin. At the same time, statins have little or no effect on PKs of L/R. PIs reduce the lipid-lowering efficacy of statins.

Simvastatin should not be used as it is highly dependent on CYP3A4 for metabolism in addition to OATP1B1-mediated uptake of the simvastatin acid. When coadministered with RTV-boosted saquinavir, the simvastatin AUC and $C_{\max }$ increased by 30 -fold [28]. Rosuvastatin is minimally exposed to CYP2C9 ( $\leq 10 \%$ of total disposition). In a study of rosuvastatin, its $\mathrm{AUC}_{0-\infty}$ and $C_{\max }$ were increased 2.1- and 4.7-fold, respectively when coadministered with L/R [31]. Samineni et al. reported nearly similar results with coprescription of darunavir/RTV and rosuvastatin [32]. This high degree of interaction may be due to significantly higher inhibition of BCRP observed with lopinavir in vitro [29]. Inhibition of BCRP decreases hepatobiliary excretion and increases intestinal absorption of rosuvastatin and atorvastatin. A higher BCRP activity in the Caucasian population compared with Asians may translate to an ethnic difference in DDI susceptibility [33]. The sodium-taurocholate cotransporting polypeptide (NTCP) is also involved in part, in the hepatic uptake of rosuvastatin [34], and RTV is an inhibitor of NTCP. Atorvastatin coadministration with $\mathrm{L} / \mathrm{R}$ increased its $\mathrm{AUC}_{0-24}$ and $C_{\max }$ by 5.9- and 4.7-fold, respectively [35] with a decrease in the formation of active metabolites. Thus, statins with a lower likelihood of interactions need to be considered.

Pitavastatin is metabolized by glucuronidation with CYP2C9 playing a minor role and the potential of DDI is least. A PK study of $\mathrm{L} / \mathrm{R}(400 \mathrm{mg} / 100 \mathrm{mg}$ twice daily) in combination with pitavastatin $4 \mathrm{mg}$ once daily showed that coadministration was safe and well tolerated [36]. At steady state ( $4 \mathrm{~h}$ after dosing), pitavastatin peak exposure $\left(C_{\max }\right)$ was unchanged and total exposure $\left(\mathrm{AUC}_{0-\tau}\right)$ was reduced by $20 \%$. Similarly, no significant DDI or safety issues were noted between pitavastatin $2 \mathrm{mg}$ daily and darunavir/RTV [37]. Pravastatin is mainly metabolized by glucuronidation with the CYP3A4 system playing a minor role. It is the least protein-bound statin, giving it a low systemic exposure. Administration of pravastatin with $\mathrm{L} / \mathrm{R}$ results in a $33 \%$ increase in pravastatin AUC [27] and dose adjustment is not required. Fluvastatin is metabolized via CYP2C9. Ritonavir is an inducer of CYP2C9 and may lead to decreased fluvastatin efficacy [38]. Pravastatin [35] and fluvastatin [39] do not have significant DDI with $\mathrm{L} / \mathrm{R}$ and there is no dose limitation; for other statins (atorvastatin and rosuvastatin), start at the lowest dose, titrate carefully, and monitor for side effects.

Ezetimibe $\mathrm{L} / \mathrm{R}$ may cause a possible reduction in ezetimibe as it is metabolized by glucuronidation; however, it can be used safely with $\mathrm{L} / \mathrm{R}$.

The DDIs of statins with $\mathrm{L} / \mathrm{R}$ are likely to be more severe in elderly patients, Asians, and patients with multiple medications. Rhabdomyolysis has been reported after the coadministration of atorvastatin and L/R with other drugs [40]. Patients of SARS-CoV-2 pneumonia with ACS, who need intensive lipid lowering, may be given a combination of pitavastatin and ezetimibe with $\mathrm{L} / \mathrm{R}$ safely for maximum lipid lowering without risk of any significant DDI. The addition of ezetimibe to statin therapy resulted in a significant reduction of lipid parameters in HIV patients not on goal despite therapy with lowdose statin prescribed with L/R [41].

Fibrates Coadministration of fenofibric acid (145 mg, single dose) with $\mathrm{L} / \mathrm{R}(400 / 100 \mathrm{mg}$, twice daily) or RTV alone (100 mg, twice daily) was studied in 13 healthy volunteers in a cross-over study. Compared with baseline, RTV decreased fenofibrate AUC by $11 \%(p>0.05)$ and $C_{\max }$ was unchanged, and L/R decreased fenofibrate AUC by $13 \%$ $(p>0.05)$ and $C_{\max }$ was unchanged. The authors concluded that fenofibrate can safely be given with either $\mathrm{L} / \mathrm{R}$ or ritonavir alone [42]. The same authors reported a significant $41 \%$ reduction in gemfibrozil exposure after 2 weeks of $L / R$ administration.

Fish Oil Patients, who are taking prescription fish oil and fenofibrate, either alone or in combination for hypertriglyceridemia, may continue it during $\mathrm{L} / \mathrm{R}$ therapy. Fish oil was found safe and effective, without any adverse effect on the pharmacokinetics of L/R [43].

PCSK9 Inhibitors Evolocumab and alirocumab are monoclonal IgG antibodies. Elimination occurs primarily via proteolytic catabolism throughout the body. Coadministration with $\mathrm{L} / \mathrm{R}$ 
has not been studied but based on metabolism and clearance a clinically significant interaction is unlikely.

\section{Lopinavir/Ritonavir + Anticoagulants}

Non-vitamin K Oral Anticoagulants Rivaroxaban and apixaban are metabolized through a variety of pathways, including CYP3A4 and BCRP. Renal elimination of rivaroxaban is P-gp dependent further complicating coadministration. In healthy volunteers, steady-state RTV increased rivaroxaban mean AUC by $153 \%$ and mean $C_{\max }$ by $55 \%$ after a single dose of $10 \mathrm{mg}$ of rivaroxaban [44]. In a report of a postoperative patient on darunavir/RTV, a single dose of rivaroxaban $10 \mathrm{mg}$ caused symptomatic bleeding from the surgical site. The prothrombin time was increased and the rivaroxaban trough level increased by eight times $(75 \mathrm{ng} / \mathrm{mL}$ compared with $9 \mathrm{ng} / \mathrm{mL}, 24 \mathrm{~h}$ after a single dose of $10 \mathrm{mg}$ ) [45]. L/R prescription with rivaroxaban may lead to increased risk of bleeding and their concomitant use was not permitted in the ROCKET AF trial (Rivaroxaban Once-daily, oral, direct factor Xa inhibition Compared with vitamin $\mathrm{K}$ antagonism for prevention of stroke and Embolism Trial in Atrial Fibrillation).

Apixaban manufacturer recommends a dose reduction to $2.5 \mathrm{mg}$ twice a day when co-administering with $\mathrm{L} / \mathrm{R}$ [46]. If the patient is already on a $2.5 \mathrm{mg}$ dose, concurrent use should be avoided. In a case series of 6 patients, reduced dose apixaban was used successfully with RTV or cobicistatboosted regimens [47]. Dabigatran is not metabolized by CYP450 and is primarily cleared through renal elimination, so significant interactions are not anticipated. However, the prodrug, dabigatran etexilate, is a substrate of P-gp and renal multidrug and toxin extrusion-1 (MATE-1) transporter. Both the transporters are inhibited by RTV. Coadministration with $\mathrm{L} / \mathrm{R}$ may result in an increase in the bioavailability of dabigatran. Peak plasma dabigatran concentration occurs $3 \mathrm{~h}$ after administration. Thus, DDI may be minimized by giving L/R after 3-4 h of dabigatran [48]. In another study, dabigatran was given either simultaneously or $2 \mathrm{~h}$ before RTV [49]. Given simultaneously, there were no statistically significant changes to dabigatran AUC or $C_{\max }$. However, dabigatran AUC and $C_{\max }$ decreased by $29 \%$ and $27 \%$, respectively, when coadministered separately to RTV. There were no significant changes to thrombin time in either arm. The authors hypothesize that no significant effect on dabigatran pharmacokinetics was seen with RTV due to its mixed induction and inhibitory effect on P-gp. CYP3A4 is minimally involved (< $4 \%$ ) in the metabolism of edoxaban; however, the drug is a substrate for P-gp. In theory, no dose adjustment is required for coadministration with potent CYP3A4 inhibitors, but no definite data is available. The European product label for edoxaban suggests a dose reduction of edoxaban to $30 \mathrm{mg}$ with strong P- gp inhibitors; however, the US product label recommends no dose modification.

In a study by Testa et al. [50], the C-trough level of nonvitamin $\mathrm{K}$ oral anticoagulants (NOACs) was measured in 12 patients of SARS-CoV-2 after 2-4 days of L/R or darunavir/ RTV administration and compared with those recorded before hospitalization. A marked increase in NOACs plasma level was seen, of which the maximum was noted for rivaroxaban, followed by edoxaban.

It is suggested to assess serum drug concentrations or anti$\mathrm{Xa}$ levels (for factor Xa inhibitors) in guiding the dose in patients with chronic kidney disease, and concomitant use of CYP3A4 and/or P-gp inhibitors. However, it may not be feasible to get these test results quickly. Thus, in critically sick patients, it will be prudent to replace NOAC with a parenteral anticoagulant.

Vitamin K Oral Anticoagulants Warfarin is a racemic mixture of two enantiomers in equal parts. (S)-warfarin (potent form) is metabolized primarily by CYP2C9, and the (R)-isomer is metabolized by CYP1A2, CYP2C19, and CYP3A4 [51]. Genetic polymorphism of CYP2C9 may be a potentially complicating factor. In healthy subjects, 10 days of L/R therapy increased CYP2C9 activity by $29 \%$ and CYP1A2 by $43 \%$ [52]. The induction of these cytochromes by L/R may result in increased warfarin metabolism and a reduction in the international normalized ratio (INR). The CYP enzyme induction may take 1 week or longer. The dose of warfarin was increased by almost three times in a patient with stable INR after starting L/R therapy [53]. In many other case reports, the dose of warfarin was increased from 40 to $140 \%$ to maintain therapeutic INR. However, intermittent RTV administration may result in inhibition of $\mathrm{CYP} 2 \mathrm{C} 9$ metabolism. It resulted in supratherapeutic INRs on days the patient took warfarin with RTV and subtherapeutic INRs on days when the patient abstained from RTV administration [54].

Similarly, in a case report of a patient of the prosthetic heart valve, RTV severely decreased the anticoagulant effect of acenocoumarol. It was not possible to maintain the desired INR despite a threefold increase in acenocoumarol dose, ultimately requiring discontinuation of RTV [55].

Initial frequent monitoring of the INR during initiation or discontinuation of $\mathrm{L} / \mathrm{R}$ in patients on vitamin $\mathrm{K}$ oral anticoagulant therapy is recommended.

Parenteral Anticoagulants L/R coadministration with heparin has not been studied. Heparin is eliminated via the reticuloendothelial system. Thus, a clinically significant interaction is unlikely.

Enoxaparin is desulfated and depolymerized in the liver and excreted predominantly renally. A clinically significant interaction is unlikely based on metabolism and clearance. 
Fondaparinux is excreted unchanged by the kidneys, limiting its DDIs.

\section{Lopinavir/Ritonavir + Calcium Channel Blockers}

All calcium channel blockers (CCB) are metabolized by CYP450, predominantly CYP3A4 (exception being nisoldipine).

Nifedipine Coadministration with RTV is reported to cause hypotension, tachycardia, edema, and pre-renal acute kidney injury $[56,57]$. Clinical monitoring and a 50\% dose reduction may be considered.

Amlodipine Amlodipine is a substrate for oxidative aromatization of its dihydropyridine ring by CYP enzymes. In a study of RTV/indinavir with amlodipine, the median amlodipine AUC increased by $89.8 \%$ [58]. A physiologically based pharmacokinetic (PBPK) model study showed that a 50\% reduced dose of amlodipine given with RTV was enough to maintain the same plasma level of amlodipine as with its full dose without RTV. The full dose of amlodipine can be resumed either immediately after stopping RTV or 5 days later under clinical monitoring [59].

Lacidipine Lacidipine is oxidized to pyridine derivatives in the liver by CYP3A4 with no parent drug detected in the urine or feces. Coadministration has not been studied. In a case report of a patient receiving multiple cardiac drugs including lacidipine and metoprolol, the addition of $\mathrm{L} / \mathrm{R}$ resulted in severe hypotension and syncope within $48 \mathrm{~h}$ [60]. Lacidipine exposure may be significantly increased by $L / R$ via inhibition of CYP3A4 and P-gp. It should be used with caution and dose titration of lacidipine should be considered.

Lercanidipine Lercanidipine is metabolized by CYP3A4. Ketoconazole, a strong CYP3A4 inhibitor, causes a 15-fold increase of the AUC and an 8-fold increase of the $C_{\max }$ for the eutomer (S)-lercanidipine. Co-prescription of $\mathrm{L} / \mathrm{R}$ and lercanidipine is contraindicated $[39,61]$.

Cilnidipine Cilnidipine is a potent $\mathrm{N}$-type $\mathrm{Ca}^{2+}$ channel blocker attenuating norepinephrine release from sympathetic nerve endings. Dehydrogenation of dihydropyridine ring of cilnidipine occurs via CYP3A4 and is crucial in its elimination. Ketoconazole competitively inhibited the metabolism of cilnidipine and a similar interaction is expected with $\mathrm{L} / \mathrm{R}$ also [62].

Diltiazem Diltiazem is largely metabolized through $\mathrm{N}$ demethylation by CYP3A to an active metabolite $\mathrm{N}$ desmethyldiltiazem. A non-CYP pathway metabolism generates another active metabolite, N-desacetyldiltiazem. RTV/ indinavir combination increased median diltiazem AUC by $26.5 \%$ [58]. Desmethyldiltiazem AUC decreased by $27.4 \%$ $(p=0.01)$ and desacetyldiltiazem AUC increased by $102.2 \%$ $(p=0.001)$. Compared with amlodipine, diltiazem has lesser interaction with RTV.

Verapamil In vitro metabolic studies indicate that verapamil is metabolized by CYPs 3A4, 1A2, 2C8, 2C9, and 2C18. RTV has significant interaction with verapamil [63] causing elevation of verapamil plasma levels [27] and a decrease in dose may be required.

Coadministration of CCB with RTV requires caution and close monitoring for toxicity (i.e., vital signs, electrocardiography (ECG) monitoring for PR interval). CCB should be initiated at a lower dose and careful dose escalation should be carried out.

\section{Lopinavir/Ritonavir + Antiarrhythmics}

Cardiac arrhythmias were noted in $16.7 \%$ of hospitalized COVID-19 patients and were more common in ICU patients compared with non-ICU patients $(44.4 \%$ vs. $6.9 \%)$ [2].

Amiodarone Amiodarone is metabolized by CYP3A4, CYP2C8, and CYP1A1 to an active metabolite [mono-Ndesethylamiodarone (MDEA)]. It is a substrate for P-gp. Amiodarone and MDEA also inhibit CYPs 1A1/2, 2A6, 2B6, 2C9/19, 3A4, 2D6, and P-gp potentially causing accumulation of PIs. Serious side effects have been reported with its coadministration with indinavir and darunavir [64, 65]. Amiodarone has a narrow therapeutic index and a number of side effects. It is suggested not to use it with RTV or to use the lowest dose to achieve therapeutic effect $[27,66]$. Serial monitoring of amiodarone serum levels until steady state is reached and frequent ECGs need to be done.

Ritonavir coadministration is contraindicated with dronedarone, encainide, flecainide, propafenone, and quinidine [67].

Lidocaine (Lignocaine) Lignocaine undergoes oxidative $\mathrm{N}$ dealkylation in the liver by CYP3A4 forming numerous metabolites. RTV coadministration with lidocaine may increase plasma concentration of lidocaine by more than threefold [68, 69].

The European summary of product information contraindicates coadministration while caution and therapeutic concentration monitoring are recommended in the USA [70].

\section{Lopinavir/Ritonavir + Beta-Blockers}

Atenolol is a hydrophilic drug. Only 5\% is metabolized by the liver and it is excreted unchanged by the kidneys. The metabolism of bisoprolol is insensitive to liver enzyme (CYP3A4) 
inhibition because it has a balanced hepatic and renal clearance. The potential interaction is of weak intensity, not requiring dose adjustment [39]. Thus, atenolol [27] and bisoprolol can be used safely with RTV.

Propranolol is metabolized by 3 routes (aromatic hydroxylation by CYP2D6, N-dealkylation followed by side-chain hydroxylation via CYPs 1A2, 2C19, 2D6, and direct glucuronidation). RTV may increase propranolol concentration although to a moderate extent. No dose adjustment is required.

Labetalol is mainly glucuronidated by UGT $1 \mathrm{~A} 1$ and $2 \mathrm{~B} 7$. Coadministration may decrease labetalol exposure due to the induction of UGT2B7 by RTV. Drug effect should be monitored and doses increased if needed.

Carvedilol, metoprolol [39], and nebivolol are metabolized by CYP2D6 and 1A2 pathway. Coadministration may result in increased levels of these beta-blockers to a moderate extent. The risk of carvedilol toxicity with PIs (especially in CYP2D6 slow metabolizers) exists.

$\mathrm{L} / \mathrm{R}$ may increase the PR interval in ECG in some patients. The clinical significance of coadministration of $\mathrm{L} / \mathrm{R}$ with betablockers on PR interval in ECG is unclear. ECG monitoring is advisable [39].

\section{Lopinavir/Ritonavir + Drugs for Pulmonary Hypertension}

Phosphodiesterase-5 Inhibitors In a study of normal male volunteers, RTV increased sildenafil AUC and $C_{\max }$ by 11 -fold and 3.9-fold respectively [71]. However, the PK of RTV was not affected by sildenafil. A lower sildenafil dose of $25 \mathrm{mg}$ every $48 \mathrm{~h}$ has been suggested for patients receiving RTV [39]. However, WHO guidelines [70] and product insert of L/R [66] do not advise concomitant use of sildenafil with darunavir/RTV and L/R in patients of pulmonary arterial hypertension (PAH) due to the potential of sildenafil-associated serious adverse events.

Coadministration of tadalafil (20 $\mathrm{mg}$ single dose) and RTV (200 mg twice daily) increased tadalafil AUC by $124 \%$ without modifying the $C_{\max }$ [72]. In a PK study, the tadalafil level was increased significantly (2.33 (2.02-2.69)) when administered with the first dose of tipranavir/RTV, but not when tipranavir/RTV steady state was reached (1.01 (0.83-1.21)) [73]. In patients on therapy with tadalafil, it is recommended to stop tadalafil at least $24 \mathrm{~h}$ prior to starting L/R. Once a steady state of $\mathrm{L} / \mathrm{R}$ is reached, preferably after at least 1 week of its initiation, the tadalafil can be resumed at $20 \mathrm{mg}$ once daily dose. The dose can be further increased to $40 \mathrm{mg}$ once daily based upon individual tolerability [66].

Concomitant use of avanafil or vardenafil with RTV is contraindicated [66]. It is important to note that recommendations for coadministration of phosphodiesterase-5 inhibitors and PIs are different for patients with PAH than those with erectile dysfunction.
Endothelin-1 Receptor Antagonists Bosentan is a substrate for CYP3A4 and OATP. Co-prescription with $L / R$ increased bosentan concentration up to 48 times $(+4700 \%)$ on day 4 , gradually dropping to 5 times at a steady state. The combination is poorly tolerated [74]. In patients on bosentan, discontinuation of its use is advised at least $36 \mathrm{~h}$ prior to initiation of L/R. Depending on individual tolerability, bosentan should be resumed at $62.5 \mathrm{mg}$ once daily or every other day after at least 10 days of initiation of $L / R$ [66]. Bosentan is a CYP3A4 inducer and slightly reduces the exposure of $\mathrm{L} / \mathrm{R}$.

Ambrisentan is metabolized by glucuronidation via several UGT isozymes (UGT1A9, UGT2B7, UGT1A3) and to a lesser extent by CYP3A4 and CYP2C19. It is a substrate of P-gp and OATP1B1 also. Ambrisentan (5 mg once daily) in combination with RTV (100 mg once daily) was studied in healthy volunteers $(n=42)$ for 10 days [75]. There was no clinically relevant effect on ambrisentan $\left(C_{\max }\right.$ increased by $7 \%$; AUC decreased by $5 \%$ ) or ritonavir ( $C_{\max }$ decreased by $2 \%$; AUC decreased by $3 \%$ ). No dose adjustment was required. Thus, the patients on bosentan therapy may be safely transitioned to ambrisentan [76] before starting $\mathrm{L} / \mathrm{R}$ to avoid adverse events.

Macitentan is metabolized mainly by CYP3A4 and to a lesser extent by CYPs 2C19, 2C9, and 2C8. RTV could potentially increase macitentan exposure. As macitentan is not a substrate of OATPs, the magnitude of interaction is lower than that seen with bosentan. No dose adjustment is recommended, but caution is required [77].

Riociguat Riociguat is a soluble guanylate cyclase (sGC) stimulator indicated for the treatment of adult patients with PAH. Riociguat is metabolized by CYP1A1, CYP3A4, CYP3A5, CYP2C8, and CYP2J2. Riociguat and its main active metabolite are also substrate of P-gp and BCRP. Ritonavir is expected to increase riociguat exposure. In a study of $9 \mathrm{HIV}$-infected adults, riociguat exposure was slightly increased when administered with an RTV-boosted triple regimen [78]. It may be because CYP1A1 is the predominant enzyme in metabolic clearance of riociguat. The European and US prescribing information recommend to start riociguat at a dose of $0.5 \mathrm{mg}$ three times daily in patients on stable doses of RTV and to monitor for signs and symptoms of hypotension [79, 80]. However, no information is available on starting RTV in patients with PAH and on a stable dosage of riociguat.

\section{Lopinavir/Ritonavir + Angiotensin-Converting Enzyme Inhibitors}

The majority of angiotensin-converting enzyme inhibitors (ACEIs) except lisinopril are converted by hepatic carboxylesterases to their active diacid metabolite.

Captopril and ritonavir DDIs are not known and unlikely. Captopril is largely excreted in urine (about half 
is excreted unchanged and rest as disulfide and other metabolites).

Lisinopril is excreted entirely unchanged into the urine via glomerular filtration. Thus, a significant interaction with $L / R$ is unlikely.

Enalapril is hydrolyzed in the liver to enalaprilat and both compounds are excreted in urine and feces. The DDI with RTV has not been studied but unlikely.

Ramipril and perindopril are hydrolyzed to AMs. Based on metabolism and clearance, clinically significant interactions with RTV are unlikely.

No DDI between currently used ACEIs and L/R is reported [39].

\section{Lopinavir/Ritonavir + Angiotensin II Receptor Blockers}

Losartan may have increased effect when coadministered with ritonavir and nelfinavir because of the induction of CYP2C9 and the expected increase in the formation of the active metabolite, E-3174 [39].

The CYP 450-mediated drug interactions between valsartan and RTV are unlikely because of the low extent of metabolism of valsartan. In vitro studies indicate that valsartan is a substrate of OATP1B1 and the hepatic efflux transporter MRP2. Coadministration of the inhibitor of the efflux transporter (e.g., RTV) may increase the systemic exposure to valsartan [81]. RTV inhibits OATP1B1 in vitro but is unlikely to inhibit it in vivo, in the range of concentrations obtained when used as a PK enhancer.

Telmisartan is not metabolized by CYP450 isoenzymes and is mostly excreted unchanged in feces. There is no potential for any significant interaction with RTV.

Candesartan is mainly eliminated unchanged via urine and bile. A clinically significant interaction with $L / R$ is unlikely based on metabolism and clearance.

There is a potential of the reduced effect of irbesartan and no change for olmesartan when co-prescribed with $L / R$ [39].

\section{Lopinavir/Ritonavir + Positive Inotropic Agents}

Digoxin Digoxin is eliminated in urine $(60 \%)$ mainly by passive filtration with P-gp-mediated excretion playing a lesser role. Approximately 25\% is secreted into bile by P-gp in the canalicular membrane of the hepatocytes. Digoxin is also a substrate for OATP-8 located on hepatocytes. Ritonavir causes P-gp and OATP inhibition in the liver leading to increased digoxin level. In a study by Ding et al. in healthy male volunteers, a single IV dose of digoxin $(0.5 \mathrm{mg})$ was given on the third day of RTV (300 mg twice daily). Ritonavir increased digoxin AUC by $86 \%$ and volume of distribution by $77 \%$; non-renal and renal digoxin clearance were decreased by $48 \%$ and $35 \%$, respectively. Digoxin terminal half-life in plasma was increased by $156 \%$ [82]. In another study, a single oral dose of digoxin
(0.4 mg) was given on day 14 of RTV (200 mg twice daily). Ritonavir increased digoxin AUC by $22 \%$ and had no effect on $C_{\max }$. Overall, $75 \%$ (9/12) of subjects had higher concentrations of digoxin after RTV administration [83]. Thus, a significant impact of RTV on renal clearance of digoxin is seen in initial days and it reduces gradually over 2 weeks. Similarly, 2 weeks of saquinavir/ RTV (1000/100 mg twice daily) with a single oral dose of digoxin $(0.5 \mathrm{mg})$ on day 14 , resulted in a 1.27 -fold increase in digoxin $C_{\max }$ and a 1.49-fold increase in $\mathrm{AUC}_{0-}$ 72. The changes were more marked in females than males. A trend of a longer PR interval was noted on ECG [84].

Digoxin dose should be halved in patients on digoxin, before starting L/R. Their clinical, ECG, and serum digoxin levels need intensive monitoring.

Dopamine Dopamine is metabolized by monoamine oxidase and catechol-O-methyltransferase to inactive compounds. There is little potential for dopamine to have DDI with $\mathrm{L} / \mathrm{R}$.

\section{Lopinavir/Ritonavir + Diuretics}

Furosemide Furosemide is glucuronidated mainly in the kidneys by UGT1A9 and to a lesser extent in the liver by UGT1A1. A large part of furosemide is also eliminated unchanged by kidneys. The potential of a clinically significant interaction with $\mathrm{L} / \mathrm{R}$ is unlikely.

Torasemide Torasemide is metabolized mainly by CYP2C9. Ritonavir may decrease torasemide exposure as it is a modest inducer of CYP2C9. No dosage adjustment is recommended [39].

Thiazide Diuretics Hydrochlorothiazide, chlorothiazide, and hydroflumethiazide are excreted unchanged by the kidneys via organic anion transporter (OAT1). A clinically significant interaction with $\mathrm{L} / \mathrm{R}$ is unlikely [70].

Thiazide-Like Diuretics Metolazone and chlorthalidone are largely excreted unchanged in the urine. A clinically significant interaction with $\mathrm{L} / \mathrm{R}$ is unlikely.

Indapamide is extensively metabolized by CYP3A4 [85]. Coadministration with RTV may increase indapamide concentrations. It is recommended to reduce the dose of indapamide.

\section{Lopinavir/Ritonavir + Mineralocorticoid Receptor Antagonists}

Spironolactone Spironolactone is metabolized by carboxylesterases and flavin-containing monooxygenases. Spironolactone is known to induce CYP3A4 and UGTs. However, its metabolites inhibit CYP3A4 and UGT2B7. Coadministration with $\mathrm{L} / \mathrm{R}$ has not been studied but a clinically significant interaction is unlikely [39]. 
Eplerenone Eplerenone is metabolized by CYP3A4. The DDI with $\mathrm{L} / \mathrm{R}$ has not been studied. However, following a single dose of eplerenone $100 \mathrm{mg}$ and another potent CYP3A inhibitor ketoconazole $200 \mathrm{mg}$ twice a day, eplerenone's $C_{\max }$ was 1.7-fold and AUC was 5.4-fold compared with eplerenone alone [86]. With moderate CYP3A inhibitors (e.g., verapamil, erythromycin, saquinavir, fluconazole), the maximum recommended dose of eplerenone is only $25 \mathrm{mg}$. A significant DDI between $\mathrm{L} / \mathrm{R}$ and eplerenone is expected to substantially increase eplerenone exposure and thereby increase the risk of hyperkalemia. Thus, it is prudent to switch eplerenone to spironolactone before initiating L/R therapy.

\section{Lopinavir/Ritonavir + Direct-Acting Vasodilators}

Hydralazine Hydralazine is converted to acetylated and hydroxylated metabolites. In vitro, hydralazine may weakly inhibit CYPs 3A4, 1A2, 2B6, and 2D6 [87]. A clinically significant interaction with $\mathrm{L} / \mathrm{R}$ is unlikely [70].

Minoxidil Minoxidil is metabolized by the liver primarily by glucuronidation, hydroxylation, and sulphation. The metabolism of minoxidil can be increased when combined with RTV. The major metabolites of minoxidil are pharmacologically active but less than that of the parent compound. Thus, a clinically significant interaction with RTV is unlikely. However, the addition of a beta-blocker to minoxidil therapy as a pretreatment to suppress the reflex sympathetic activation may prolong the PR interval in ECG during coadministration with $\mathrm{L} / \mathrm{R}$.

Organic Nitrates Biotransformation of glyceryl trinitrate and isosorbide dinitrate to nitric oxide is mediated by aldehyde dehydrogenase and CYP3A4 respectively. Nitric oxide formation from isosorbide dinitrate was strongly inhibited by ketoconazole in an in vitro study [88]. Therefore, the clinical effect of nitrates may be potentially reduced by L/R. The clinical relevance of this DDI is not known, and monitoring is advised. No clinically significant interaction was noticed between $\mathrm{L} / \mathrm{R}$ and amyl nitrite when the latter was used as a recreational drug by patients with AIDS [70].

Nicorandil Bioactivation of nicorandil involves denitration via the nicotinamide/ nicotinic acid pathway. It is unlikely to have DDI with $\mathrm{L} / \mathrm{R}$.

\section{Lopinavir/Ritonavir + Fibrinolytic Agents}

Streptokinase Streptokinase is metabolized proteolytically in the liver and eliminated via the kidneys. Streptokinase is unlikely to affect the disposition of $\mathrm{L} / \mathrm{R}$, or to be affected if coadministered with $\mathrm{L} / \mathrm{R}$. Metabolism of other fibrinolytic agents is similar to streptokinase.
Fibrinolytic therapy has been suggested as a viable option for stable patients of ST-elevation myocardial infarction with confirmed COVID-19 infection [89]. There is no potential interaction of $\mathrm{L} / \mathrm{R}$ with fibrinolytic agents; however, concomitant antiplatelet and anticoagulation therapy need a careful decision to avoid bleeding.

\section{Miscellaneous Medications}

Ranolazine Ranolazine is extensively metabolized by CYP3A4 and to a lesser extent by CYP2D6. It is a P-gp substrate also. Ketoconazole raises the AUC of ranolazine by 3.9-fold [90]. A significant interaction with $\mathrm{L} / \mathrm{R}$ is likely. Ranolazine inhibits $I_{\mathrm{Kr}}$ which prolongs the ventricular action potential and QT interval. The co-prescription with $\mathrm{L} / \mathrm{R}$ is contraindicated.

Ivabradine Ivabradine is metabolized by CYP3A4 [91]. A case of severe symptomatic bradycardia precipitated by adding ivabradine in a patient on RTV has been reported [92]. Coadministration of ivabradine and $L / R$ is contraindicated.

Sacubitril Sacubitril is converted to LBQ657 (sacubitrilatactive metabolite) by carboxylesterases. Sacubitril inhibits OATP1B1 and LBQ657 is a substrate of OATP1B1/3, OAT1, and OAT3. Ritonavir is an inhibitor of OATP1B1 in vitro but is unlikely to inhibit it in the dose used with lopinavir. Coadministration has not been studied but a clinically significant interaction is unlikely [93].

Methyldopa Methyldopa is excreted in urine by glomerular filtration, primarily unchanged and as the mono-O-sulfate conjugate. It is unlikely to have any DDI with $\mathrm{L} / \mathrm{R}$.

Colchicine Colchicine is being used in the treatment of acute pericarditis. Coadministration of RTV (100 mg twice daily for 5 days) and colchicine ( $0.6 \mathrm{mg}$ single dose) significantly increased colchicine $C_{\max }$ and AUC by 2.7 -fold and 3.5 -fold, respectively [94]. Life-threatening and fatal DDIs have been reported in patients with renal and/or hepatic impairment treated with colchicine and RTV. A reduction in colchicine dosage by half or an interruption of colchicine treatment is recommended in patients with normal renal or hepatic function.

Prazosin The major route of metabolism of prazosin is via Odealkylation and glucuronide formation. There is no DDI with $\mathrm{L} / \mathrm{R}$ involving cytochrome enzyme system. However, prazosin and $\mathrm{L} / \mathrm{R}$ both inhibit the activity of organic cation transporter 1 (OCT1) expressed on hepatocytes where it mediates uptake of several drugs from the blood [95]. L/R therapy is one of the exclusion criteria for patients of SARS-CoV2 pneumonia being enrolled for prazosin therapy in the 
currently ongoing "Prazosin to Prevent COVID-19 (PREVENT-COVID) trial" [96].

\section{ECG Changes with Lopinavir/Ritonavir}

PR Interval Prolongation L/R prolongs the PR interval in some patients. Cases of second- or third-degree atrioventricular block have been reported. In a study with therapeutic (400/100 $\mathrm{mg}$ BID) and supratherapeutic (800/ $200 \mathrm{mg}$ BID) doses of L/R for 3 days, the maximum mean (95\% upper confidence bound) differences from placebo, in the PR interval after baseline correction, were 24.9 $(21.5,28.3)$ and $31.9(28.5,35.3) \mathrm{ms}$ respectively [97]. $\mathrm{L} / \mathrm{R}$ should be used with caution in patients with underlying structural heart disease, pre-existing conduction abnormalities, ischemic heart disease, or cardiomyopathies, as these patients may be at an increased risk for developing cardiac conduction abnormalities [66]. The impact on the PR interval of coadministration of $L / R$ with other drugs that prolong the PR interval (including $\mathrm{CCB}$, betaadrenergic blockers, and digoxin) has not been evaluated. Therefore, caution is necessary with the coadministration of these drugs [39]. Clinical and ECG monitoring is recommended.

QT Interval Prolongation Most of the studies on the effect of PIs on QT interval have been reported in HIV-positive patients with prolonged duration of PI therapy [98, 99]. HIV positivity is a confounding factor as PI-naive HIV patients with higher viral load and lower CD4 cell count have a high prevalence of QT interval prolongation [100]. In a study involving normal healthy volunteers [101], supratherapeutic doses of darunavir/RTV demonstrated the greatest time match increase in heart rate corrected QT (Fridericia's) interval of $1.6 \mathrm{~ms}$ on day 7 of the study. The effect of PIs on QT interval may get exacerbated by concomitant use of quinolone and macrolide antibiotics, antiarrhythmics, chloroquine, hydroxychloroquine, and many other drugs [66]. It is advised to avoid using L/R in patients with congenital long QT syndrome and hypokalemia [70]. Baseline and follow-up ECG are suggested.

\section{Conclusion}

Ritonavir-boosted therapy leads to several important DDIs with cardiac medications. Patients with SARS-CoV-2 infection require antiviral therapy for a shorter period of time compared with patients with AIDS; there still exists a potential of serious DDIs. They are summarized in Table 1. Several cardiac medications, e.g., ranolazine, dronedarone, colchicine, simvastatin, and sildenafil, should not be used with L/R. For many other medications, a switch to a different molecule within the same group/class of drugs will help in the safe and effective co-prescription of these therapies. The knowledge of these potential drug interactions leads to appropriate monitoring and early identification of adverse events, avoiding iatrogenic complications.

Table 1 Key recommendations based on drug-drug interactions of lopinavir-ritonavir and cardiac medications

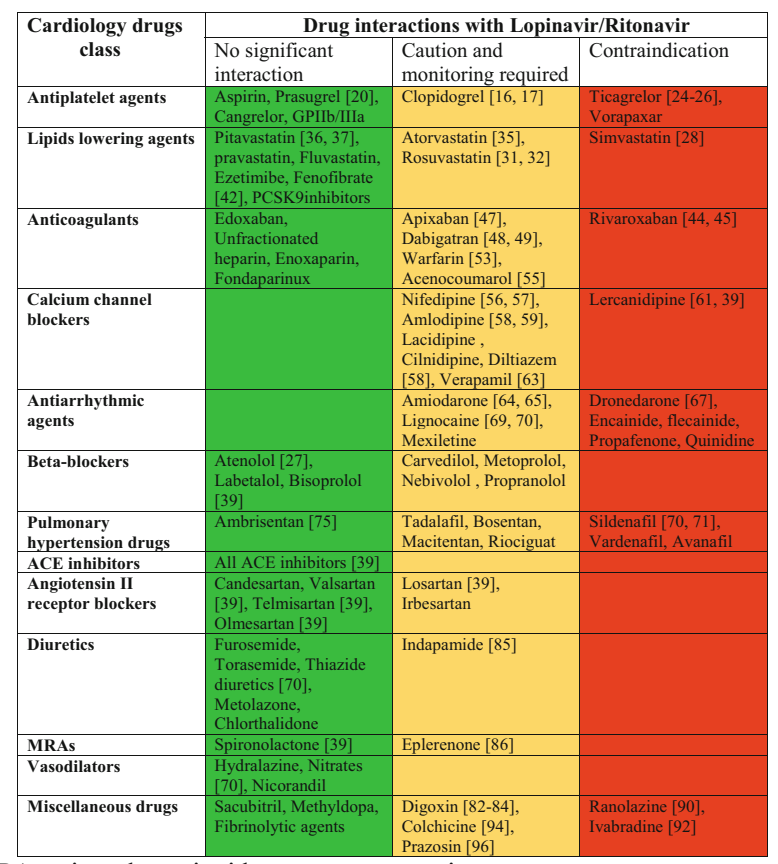

$A C E$ angiotensin-converting enzyme, MRAs mineralocorticoid receptor antagonists 
Authors' Contributions S.A. conceived and designed the study; carried out data collection, analysis, and interpretation; drafted manuscript; critical revision of the article; and final approval of the version to be published. S.K.A. undertook literature search, data collection, reviews, and data extraction; prepared table and figures; edited manuscript; and approved the final version. Both the authors agree to be accountable for all aspects of the work.

Data availability Not applicable.

\section{Compliance with Ethical Standards}

Conflict of Interest The authors declare that they have no conflict of interest.

\section{References}

1. World Health Organization. Pneumonia of unknown cause China. January 5, 2020 (https://www.who.int/csr/don/05january-2020-pneumonia-of-unkown-cause-china/en/).

2. Wang D, Hu B, Hu C, Zhu F, Liu X, Zhang J, et al. Clinical characteristics of 138 hospitalized patients with 2019 novel coronavirus-infected pneumonia in Wuhan, China. JAMA. 2020;323(11):1061-9.

3. Li B, Yang J, Zhao F, Zhi L, Wang X, Liu L, et al. Prevalence and impact of cardiovascular metabolic diseases on COVID-19 in China. Clin Res Cardiol. 2020;109(5):531-8.

4. Madjid M, Safavi-Naeini P, Solomon SD, Vardeny O. Potential effects of coronaviruses on the cardiovascular system-a review. [published online ahead of print, 2020 Mar 27]. JAMA Cardiol. 2020. https://doi.org/10.1001/jamacardio.2020.1286.

5. Sakabe M, Yoshioka R, Fujiki A. Sick sinus syndrome induced by interferon and ribavirin therapy in a patient with chronic hepatitis. C J Cardiol Cases. 2013;8(6):173-5. https://doi.org/10.1016/j. jccase.2013.08.002.

6. Demessine L, Peyro-Saint-Paul L, Gardner EM, Ghosn J, Parienti JJ. Risk and cost associated with drug-drug interactions among aging HIV patients receiving combined antiretroviral therapy in France. Open Forum Infect Dis. 2019;6(3):ofz051.

7. Nukoolkarn V, Lee VS, Malaisree M, Aruksakulwong O, Hannongbua S. Molecular dynamic simulations analysis of ritonavir and lopinavir as SARS-CoV 3CL(pro) inhibitors. J Theor Biol. 2008;254(4):861-7.

8. Liu X, Wang XJ. Potential inhibitors against 2019-nCoV coronavirus $\mathrm{M}$ protease from clinically approved medicines. J Genet Genomics. 2020;47(2):119-21. https://doi.org/10.1016/j.jgg. 2020.02.001.

9. Cao B, Wang Y, Wen D, Liu W, Wang J, Fan G, et al. A trial of lopinavir-ritonavir in adults hospitalized with severe Covid-19. N Engl J Med. 2020;382(19):1787-99. https://doi.org/10.1056/ NEJMoa2001282.

10. Chan KS, Lai ST, Chu CM, Tsui E, Tam CY, Wong MM, et al. Treatment of severe acute respiratory syndrome with lopinavir/ ritonavir: a multicentre retrospective matched cohort study. Hong Kong Med J. 2003;9:399-406.

11. Boccara F, Lang S, Meuleman C, Ederhy S, Mary-Krause M, Costagliola D, et al. HIV and coronary heart disease: time for a better understanding. J Am Coll Cardiol. 2013;61:511-23.

12. Capodanno D, Alfonso F, Levine GN, Valgimigli M, Angiolillo DJ. ACC/AHA versus ESC guidelines on dual antiplatelet therapy: JACC Guideline Comparison. J Am Coll Cardiol. 2018;72(23):2915-31.
13. Miners JO. Drug interactions involving aspirin (acetylsalicylic acid) and salicylic acid. Clin Pharmacokinet. 1989;17:327-44.

14. Renga B, Mencarelli A, Cipriania S, et al. In vivo administration of ritonavir worsens intestinal damage caused by cyclooxygease inhibitors. Eur J Phar. 2014;723:194-201. https://doi.org/10.1016/ j.ejphar.2013.11.035.

15. Jens J, Kort JJ, Aslanyan S, Scherer J, et al. Effects of tipranavir, darunavir, and ritonavir on platelet function, coagulation, and fibrinolysis in healthy volunteers. Curr HIV Res. 2011;9:237-46.

16. Itkonen MK, Tornio A, Lapatto-Reiniluoto O, Neuvonen M, Neuvonen PJ, Niemi M, et al. Clopidogrel increases dasabuvir exposure with or without ritonavir, and ritonavir inhibits the bioactivation of clopidogrel. Clin Pharmacol Ther. 2019;105(1): 219-28. https://doi.org/10.1002/cpt.1099.

17. Bravo I, Alvarez H, Marino A, Clotet B, Molto J. Recurrent coronary disease in HIV-infected patients: role of drug-drug interactions. Br J Clin Pharmacol. 2018;84:1617-9. https://doi.org/10. 1111/bcp.13583.

18. Ancrenaz V, Déglon J, Samer C, Staub C, Dayer P, Daali Y, et al. Pharmacokinetic interaction between prasugrel and ritonavir in healthy volunteers. Basic Clin Pharmacol Toxicol. 2013;112(2): 132-7. https://doi.org/10.1111/j.1742-7843.2012.00932.x.

19. Daali Y, Ancrenaz V, Bosilkovska M, Dayer P, Desmeules J. Ritonavir inhibits the two main prasugrel bioactivation pathways in vitro: a potential drug-drug interaction in HIV patients. Metabolism. 2011;60(11):1584-9. https://doi.org/10.1016/j. metabol.2011.03.015.

20. Marsousi N, Daali Y, Fontana P, Reny JL, Ancrenaz-Sirot V, Calmy A, et al. Impact of boosted antiretroviral therapy on the pharmacokinetics and efficacy of clopidogrel and prasugrel active metabolites. Clin Pharmacokinet. 2018;57(10):1347-54. https:// doi.org/10.1007/s40262-018-0637-6.

21. Jernberg T, Payne CD, Winters KJ, Darstein C, Brandt JT, Jakubowski JA, et al. Prasugrel achieves greater inhibition of platelet aggregation and a lower rate of non-responders compared with clopidogrel in aspirin-treated patients with stable coronary artery disease. Eur Heart J. 2006;27:1166-73.

22. Wiviott SD, Braunwald E, McCabe CH, TRITON-TIMI 38 Investigators. Prasugrel versus clopidogrel in patients with acute coronary syndromes. N Engl J Med. 2007;357:2001-15.

23. Wiviott SD, Trenk D, Frelinger AL, O'Donoghue M, Neumann FJ, Michelson AD, et al. Prasugrel compared to high loading and maintenance dose clopidogrel in patients with planned percutaneous coronary intervention: the PRINCIPLE-TIMI 44 trial. Circulation. 2007;116:2923-32.

24. Dobesh PP, Oestreich JH. Ticagrelor: pharmacokinetics, pharmacodynamics, clinical efficacy, and safety. Pharmacotherapy. 2014;34(10):1077-90.

25. Marsousi N, Samer CF, Fontana P, Reny JL, Rudaz S, Desmeules JA, et al. Coadministration of ticagrelor and ritonavir: toward prospective dose adjustment to maintain an optimal platelet inhibition using the PBPK approach. Clin Pharmacol Ther. 2016;100(3): 295-304

26. Azran M, Tanaka KA. Interaction between ticagrelor and CYP3A4 inhibitor: importance of P2Y12 function testing to assess platelet recovery before surgery. J Cardiothorac Vasc Anesth. 2019;33(11):3221-2.

27. Panel on Antiretroviral Guidelines for adults and adolescents. Guidelines for the use of antiretroviral agents in adults and adolescents with HIV. Department of health and human services. Available at https://aidsinfo.nih.gov/contentfiles/lvguidelines/ adultandadolescentgl.pdf (Accessed 1 May 2020).

28. Fichtenbaum CJ, Gerber JG, Rosenkranz SL, Segal Y, Aberg JA, Blaschke T, et al. Pharmacokinetic interactions between protease inhibitors and statins in HIV seronegative volunteers: ACTG Study A5047. AIDS. 2002;16(4):569-77. 
29. Weiss J, Rose J, Storch CH, Ketabi-Kiyanvash N, Sauer A, Haefeli WE, et al. Modulation of human BCRP (ABCG2) activity by anti-HIV drugs. J Antimicrob Chemother. 2007;59:238-45.

30. Hirano M, Maeda K, Shitara Y, Sugiyama Y. Contribution of OATP2 (OATP1B1) and OATP8 (OATP1B3) to the hepatic uptake of pitavastatin in humans. J Pharmacol Exp Ther. 2004;311: $139-46$.

31. Kiser JJ, Gerber JG, Predhomme JA, Wolfe P, Flynn DM, Hoody DW. Drug/drug interaction between lopinavir/ritonavir and rosuvastatin in healthy volunteers. J Acquir Immune Defic Syndr. 2008;47:570-8.

32. Samineni D, Desai PB, Sallans L, Fichtenbaum CJ. Steady-state pharmacokinetic interactions of darunavir/ritonavir with lipidlowering agent rosuvastatin. J Clin Pharmacol. 2012;52(6):92231. https://doi.org/10.1177/0091270011407494.

33. Birmingham BK, Bujac SR, Elsby R, Azumaya CT, Wei C, Chen $\mathrm{Y}$, et al. Impact of ABCG2 and SLCO1B1 polymorphisms on pharmacokinetics of rosuvastatin, atorvastatin and simvastatin acid in Caucasian and Asian subjects: a class effect? Eur J Clin Pharmacol. 2015;71(3):341-55.

34. Ho RH, Tirona RG, Leake BF, Glaeser H, Lee W, Lemke CJ, et al. Drug and bile acid transporters in rosuvastatin hepatic uptake: function, expression, and pharmacogenetics. Gastroenterology. 2006;130(6):1793-806.

35. Carr RA, Andre AK, Bertz RJ, Lam W, Chang M, Chen P, Williams L, Bernstein B, Sun E. Concomitant administration of ABT-378/ritonavir (ABT-378/r) results in a clinically important pharmacokinetics (PK) interaction with atorvastatin (ATO) but not pravastatin (PRA). Abstract 1644, 40th Interscience Conference on Antimicrobial Agents and Chemotherapy (ICAAC), Toronto, Canada, September 17-20, 2000

36. Morgan RE, Campbell SE, Suehira K, Sponseller CA, Yu CY, Medlock MM. Effects of steady-state lopinavir/ritonavir on the pharmacokinetics of pitavastatin in healthy adult volunteers. $\mathrm{J}$ Acquir Immune Defic Syndr. 2012;60(2):158-64.

37. Malvestutto CD, Ma Q, Morse GD, Underberg JA, Aberg JA. Lack of pharmacokinetic interactions between pitavastatin and efavirenz or darunavir/ritonavir. J Acquir Immune Defic Syndr. 2014;67(4):390-6. https://doi.org/10.1097/QAI. 0000000000000333 .

38. Chastain DB, Stover KR, Riche DM. Evidence-based review of statin use in patients with HIV on antiretroviral therapy. J Clin Transl Endocrinol. 2017;8:6-14.

39. Guidelines. Version 8.1. European AIDS Clinical Society. Updated October 2016. Available at http://www.eacsociety.org/ guidelines/eacs-guidelines/eacs-guidelines.html. (Accessed 10 May 2020).

40. Mah Ming JB, Gill MJ. Drug-induced rhabdomyolysis after concomitant use of clarithromycin, atorvastatin, and lopinavir/ ritonavir in a patient with HIV. AIDS Patient Care STDs. 2003;17(5):207-10.

41. van den Berg-Wolf M, Klibanov OM, Gaughan JP, Tedaldi EM. Ezetimibe combined with low-dose statin effectively lowers LDL in protease inhibitor treated patients. AIDS Patient Care STDs. 2008;22(6):483-8. https://doi.org/10.1089/apc.2007.0206.

42. Gordon LA, Malati CY, Hadigan C, McLaughlin M, Alfaro RM, Calderón $\mathrm{MM}$, et al. Lack of an effect of ritonavir alone and lopinavir-ritonavir on the pharmacokinetics of fenofibric acid in healthy volunteers. Pharmacotherapy. 2016;36(1):49-56.

43. Gerber JG, Kitch DW, Fichtenbaum CJ, Zackin RA, Charles S, Hogg E, et al. Fish oil and fenofibrate for the treatment of hypertriglyceridemia in HIV-infected subjects on antiretroviral therapy: results of ACTG A5186 [published correction appears in J Acquir Immune Defic Syndr. 2009 Mar 1;50(3):343. J Acquir Immune Defic Syndr. 2008;47(4):459-66.
44. Mueck W, Kubitza D, Becka M. Co-administration of rivaroxaban with drugs that share its elimination pathways: pharmacokinetic effects in healthy subjects. Br J Clin Pharmacol. 2013;76(3):45566.

45. Corallo CE, Grannell L, Tran H. Postoperative bleeding after administration of a single dose of rivaroxaban to a patient receiving antiretroviral therapy. Drug Saf Case Rep. 2015;2(1):11. https:// doi.org/10.1007/s40800-015-0014-4.

46. Eliquis ${ }^{\circledR}$ [package insert]. Princeton: Bristol-Myers Squibb Company, 2018.

47. Nisly SA, Stevens BN. Ritonavir- or cobicistat-boosted antiretroviral therapy and direct oral anticoagulants: a case for apixaban. Int J STD AIDS. 2019;30(7):718-22.

48. Barco S, Coppens M, van den Dool EJ, van de Kerkhof D, Stroobants AK, Middeldorp S. Successful co-administration of dabigatran etexilate and protease inhibitors ritonavir/lopinavir in a patient with atrial fibrillation. Thromb Haemost. 2014;112(4): 836-8.

49. Kumar P, Gordon LA, Brooks KM, et al. Differential influence of the antiretroviral pharmacokinetic enhancers ritonavir and cobicistat on intestinal P-glycoprotein transport and the pharmacokinetic/pharmacodynamic disposition of dabigatran. Antimicrob Agents Chemother. 2017;61(11):e01201-17.

50. Testa S, Prandoni P, Paoletti O, Morandini R, Tala M, Dellanoce $\mathrm{C}$, et al. Direct oral anticoagulant plasma levels' striking increase in severe COVID-19 respiratory syndrome patients treated with antiviral agents: the Cremona experience. J Thromb Haemost. 2020;18(6):1320-3. https://doi.org/10.1111/jth.14871.

51. Ufer M. Comparative pharmacokinetics of vitamin $\mathrm{K}$ antagonists. Clin Pharmacokinet. 2005;44(12):1227-46.

52. Yeh RF, Gaver VE, Patterson KB, Rezk NL, Baxter-Meheux F, Blake MJ, et al. Lopinavir/ritonavir induces the hepatic activity of cytochrome P450 enzymes CYP2C9, CYP2C19, and CYP1A2 but inhibits the hepatic and intestinal activity of CYP3A as measured by a phenotyping drug cocktail in healthy volunteers. $\mathrm{J}$ Acquir Immune Defic Syndr. 2006;42(1):52-60.

53. Hughes CA, Freitas A, Miedzinski LJ. Interaction between lopinavir/ritonavir and warfarin. CMAJ. 2007;177(4):357-9.

54. Newshan G, Tsang P. Ritonavir and warfarin interaction. AIDS. 1999;13(13):1788-9. https://doi.org/10.1097/00002030199909100-00028.

55. Llibre JM, Romeu J, López E, Sirera G. Severe interaction between ritonavir and acenocoumarol. Ann Pharmacother. 2002;36(4):621-3.

56. Baezaa MT, Merinoa E, Boixa V, Climen E. Nifedipinelopinavir/ritonavir severe interaction: a case report. AIDS. 2007;21(1):119-20.

57. Rossi DR, Rathbun RC, Slater LN. Symptomatic orthostasis with extended-release nifedipine and protease inhibitors. Pharmacotherapy. 2002;22(10):1312-6. https://doi.org/10.1592/ phco.22.15.1312.33478.

58. Glesby MJ, Aberg JA, Kendall MA, Fichtenbaum CJ, Hafner R, Hall S, et al. Pharmacokinetic interactions between indinavir plus ritonavir and calcium channel blockers. Clin Pharmacol Ther. 2005;78(2):143-53.

59. Mukherjee D, Zha J, Menon RM, Shebley M. Guiding dose adjustment of amlodipine after co-administration with ritonavir containing regimens using a physiologically-based pharmacokinetic/ pharmacodynamic model. J Pharmacokinet Pharmacodyn. 2018;45(3):443-56.

60. Puech R, Gagnieu MC, Planus C, Charpiat B, Boibieux A, Ferry $\mathrm{T}$, et al. Extreme bradycardia due to multiple drug-drug interactions in a patient with HIV post-exposure prophylaxis containing lopinavir-ritonavir. Br J Clin Pharmacol. 2011;71(4):621-3.

61. Zanidip (Lercanidipine hydrochloride) Summary of Product Characteristics (SmPC). October 2019. Recordati, Bracknell, 
RG12 1US, UK. https://www.medicines.org.uk/emc/product/191/ smpc

62. Liu XQ, Zhao Y, Li D, Qian ZY, Wang GJ. Metabolism and metabolic inhibition of cilnidipine in human liver microsomes. Acta Pharmacol Sin. 2003;24(3):263-8.

63. Calan (verapamil hydrochloride tablets) [product monograph]. G D Searle (division of Pfizer Inc), NY,NY10017.

64. Lohman JJ, Reichert LJ, Degen LP. Antiretroviral therapy increases serum concentrations of amiodarone. Ann Pharmacother. 1999;33(5):645-6.

65. Alsindi F, Murphy C, Martin D. Amiodarone induced torsade de pointes in a patient with HIV on antiretroviral therapy. Grand Rounds. 2010;10:28-33. https://doi.org/10.1102/1470-5206. 2010.0006.

66. KALETRA(R) oral film coated tablets, oral solution, lopinavir ritonavir oral film coated tablets, oral solution. Product Insert. AbbVie Inc. (per FDA), North Chicago, IL, 2013.

67. NORVIR (Ritonavir). Summary of product characteristics. 26 August 1996 (revised 17 January 2013). Abbott Laoratories Limited, Abbott House, Maidenhead, Berkshire.

68. Trujillo TC, Nolan PE. Antiarrhythmic agents: drug interactions of clinical significance. Drug Saf. 2000;23(6):509-32.

69. Dekkers BGJ, Bierman WFW, Touw DJ, Alffenaar JC. Relevance of the drug-drug interactions between lidocaine and the pharmacokinetic enhancers ritonavir and cobicistat. AIDS. 2019;33(6): 1100-2.

70. WHO. Consolidated guidelines on the use of antiretroviral drugs for treating and preventing HIV infection-Recommendations for a public health approach-Second edition 2016. https://apps.who.int/ iris/bitstream/handle/10665/208825/9789241549684_eng.pdf? sequence $=1$

71. Muirhead GJ, Wulff MB, Fielding A, Kleinermans D, Neil BN. Pharmacokinetic interactions between sildenafil and saquinavir/ ritonavir. Br J Clin Pharmacol. 2000;50(2):99-107.

72. Cialis (tadalafil) full prescribing information. Indianapolis, IN: Eli-Lilly; 2007. Available at: http://pi.lilly.com/us/cialis-pi.pdf (accessed date is 2020).

73. Garraffo R, Lavrut T, Ferrando S, Durant J, Rouyrre N, MacGregor TR, et al. Effect of tipranavir/ritonavir combination on the pharmacokinetics of tadalafil in healthy volunteers. J Clin Pharmacol. 2011;51(7):1071-8.

74. Dingemanse J, van Giersbergen PLM, Patat A, Nilsson PN. Mutual pharmacokinetic interactions between Bosentan and lopinavir/ritonavir in healthy participants. Antivir Ther. 2010;15(2):157-63.

75. Gillies H, Wang X, Staehr P, Zack J. PAH therapy in HIV: lack of drug-drug interaction between ambrisentan and ritonavir. American Thoracic Society International Conference, Denver, CO, USA [abstract]. Am J Respir Crit Care Med. 2011;183: A5913.

76. Dawson A, Reddecliffe S, Coghlan C, Schreiber BE, Coghlan JG. Safety and feasibility audit of a home-based drug-transitioning approach for patients with pulmonary arterial hypertension: an observational study. Eur J Cardiovasc Nurs. 2018;17(7):612-8. https://doi.org/10.1177/1474515118769534.

77. de Kanter R, Sidharta PN, Delahaye S, Gnerre C, Segrestaa J, Buchmann S, et al. Physiologically-based pharmacokinetic modeling of macitentan: prediction of drug-drug interactions. Clin Pharmacokinet. 2016;55(3):369-80. https://doi.org/10.1007/ s40262-015-0322-y.

78. DeJesus E, Saleh S, Cheng S, van der Mey D, Becker C, Frey R, et al. Pharmacokinetic interaction of riociguat and antiretroviral combination regimens in HIV-1-infected adults. Pulm Circ. 2019;9(2):1-10.
79. Bayer AG, Adempas (riociguat) Summary of product characteristics. Available at: https://www.ema.europa.eu/en/documents/ product-information/adempas-epar-product-information_en.pdf

80. Bayer AG. Adempas (riociguat) highlights of US prescribing information. 2018. Available at: http://labeling.bayerhealthcare. $\mathrm{com} / \mathrm{html} /$ products/pi/Adempas_PI.pdf (accessed 2020).

81. Diovan (Valsartan) prescribing information. Novartis Pharmaceuticals Corp. East Hanover, NJ 07936 https://www. accessdata.fda.gov/drugsatfda_docs/label/2017/021283s50lbl. pdf (accessed date is 2020).

82. Ding R, Tayrouz Y, Riedel KD, Burhenne J, Weiss J, Mikus G, et al. Substantial pharmacokinetic interaction between digoxin and ritonavir in healthy volunteers. Clin Pharmacol Ther. 2004;76(1): 73-84.

83. Penzak SR, Shen JM, Alfaro RM, Remaley AT, Natarajan V, Falloon J. Ritonavir decreases the nonrenal clearance of digoxin in healthy volunteers with known MDR1 genotypes. Ther Drug Monit. 2004;26(3):322-30.

84. Schmitt C, Kaeser B, Riek M, Bech N, Kreuzer C. Effect of saquinavir/ritonavir on P-glycoprotein activity in healthy volunteers using digoxin as a probe. Int $\mathrm{J}$ Clin Pharmacol Ther. 2010;48:192-9.

85. Sun H, Moore C, Dansette PM, Kumar S, Halpert JR, Yost GS. Dehydrogenation of the indoline-containing drug 4-chloro-N-(2methyl-1-indolinyl)-3 sulfamoylbenzamide (indapamide) by CYP3A4: correlation with in silico predictions. Drug Metab Dispos. 2009;37:672-84.

86. Eplerenone $\left(\operatorname{Inspra}^{\circledR}\right)$ full prescribing information. https://www. accessdata.fda.gov/drugsatfda_docs/label/2016/021437s0131bl. pdf

87. Yang X, Johnson N, Di L. Evaluation of cytochrome P450 selectivity for hydralazine as an aldehyde oxidase inhibitor for reaction phenotyping. J Pharm Sci. 2019;108(4):1627-30.

88. Minamiyama $\mathrm{Y}$, Takemura $\mathrm{S}$, Akiyama $\mathrm{T}$, Imaoka $\mathrm{S}$, Inoue $\mathrm{M}$, Funae Y, et al. Isoform of cytochrome P450 on organic nitrate derived nitric oxide release in human heart vessels. FEBS Lett. 1999;452:165-8.

89. Welt FGP, Shah PB, Aronow HD, Bortnick AE, Henry TD, Sherwood MW, et al. Catheterization laboratory considerations during the coronavirus (COVID-19) pandemic-American College of Cardiology's Interventional Council and the Society for Cardiovascular Angiography and Interventions. J Am Coll Cardiol. 2020;75(18):2372-5.

90. Jerling M. Clinical pharmacokinetics of ranolazine. Clin Pharmacokinet. 2006;45(5):469-91. https://doi.org/10.2165/ 00003088-200645050-00003.

91. Chaudhary R, Garg J, Krishnamoorthy P, Shah N, Lanier G, Martinez MW, et al. Ivabradine: heart failure and beyond. J Cardiovasc Pharmacol Ther. 2016;21(4):335-43. https://doi.org/ 10.1177/1074248415624157.

92. Romero-Leon JM, Galvez-Contreras MC, Diez-Garcia LF. Symptomatic bradycardia and heart failure triggered by ivabradine in a patient receiving antiretroviral therapy. Rev Esp Cardiol. 2016;69(5):529-30.

93. Hanna I, Alexander N, Crouthamel MH, Davis J, Natrillo A, Tran $\mathrm{P}$, et al. Transport properties of valsartan, sacubitril and its active metabolite (LBQ657) as determinants of disposition. Xenobiotica. 2018;48(3):300-13. https://doi.org/10.1080/00498254.2017. 1295171.

94. Terkeltaub RA, Furst DE, Digiacinto JL, Kook KA, Davis MW. Novel evidence-based colchicine dose-reduction algorithm to predict and prevent colchicine toxicity in the presence of cytochrome P450 3A4/P-glycoprotein inhibitors [published correction appears in Arthritis Rheum. 2011 Nov;63(11):3521. Dosage error in article text. Arthritis Rheum. 2011;63(8):2226-37. 
95. Moss DM, Liptrott NJ, Siccardi M, Owen A. Interactions of antiretroviral drugs with the SLC22A1 (OCT1) drug transporter. Front Pharmacol. 2015;6:78.

96. Bettegowda C. Prazosin to Prevent COVID-19 (PREVENTCOVID Trial). https://clinicaltrials.gov/ct2/show/NCT04365257

97. Da Silva B, Li J, Lin Y, Noertersheuser PA, Awni WM, Klein CE, et al. Evaluation of the impact of lopinavir/ritonavir (LPV/r) and ritonavir (RTV) on PR interval: results from a thorough QT study. JIAS. 2008;11:101. https://doi.org/10.1186/1758-2652-11-S1P101.

98. Rathbun CR, Liedtke MD, Blevins SM, Harrison D, Lockhart SM, Salvaggio M, et al. Electrocardiogram abnormalities with atazanavir and lopinavir/ritonavir. HIV Clin Trials. 2009;10(5): 328-36. https://doi.org/10.1310/hct1005-328.

99. Soliman EZ, Lundgren JD, Roediger MP, Duprez DA, Temesgen $\mathrm{Z}$, Bickel M, et al. Boosted protease inhibitors and the electrocardiographic measures of QT and PR durations. AIDS. 2011;25(3): 367-77. https://doi.org/10.1097/QAD.0b013e328341dcc0.
100. Qaqa AY, Shaaban H, DeBari VA, Phung S, Slim J, Costeas CA, et al. Viral load and CD4p cell count as risk factors for prolonged QT interval in HIV-infected subjects: a cohort-nested case-control study in an outpatient population. Cardiology. 2010;117(2):10511.

101. Vangeneugden T, Sekar VJ, Lefebvre E, De Paepe E, De Pauw M, Koester A, Mariën K, Spinosa-Guzman S, Hoetelmans RM, Miralles D. QTc study of darunavir co-administered with lowdose ritonavir in healthy, HIV-negative volunteers. 4th IAS Conference on HIV Pathogenesis, Treatment and Prevention, Sydney, Australia, 22-25 July 2007.

Publisher's Note Springer Nature remains neutral with regard to jurisdictional claims in published maps and institutional affiliations. 